\title{
NOTES ON INSCRIPTIONES GRAECAE V. 1.
}

THE editor of the recent volume of the Inscriptiones Graecae, which comprises the inscriptions of Laconia and Messenia, is to be congratulated upon the conclusion of a long and arduous task, and still more upon the careful and scholarly manner in which that task has been accomplished. Undertaken originally by Max Fraenkel, who devoted to it the few months of life which remained to him after editing the Argolic inscriptions (I.G. iv.), it was carried on by Hans von Prott, and after his sudden death in 1903 was entrusted by the Berlin Academy to Walter Kolbe, now Professor at the University of Rostock, who after almost ten years has completed it in a manner worthy of the august body under whose auspices it has been carried through. Out of 1626 inscriptions, 158 had not been previously published, while the texts of those which were already known have gained much by correction, based usually upon the copies of the editor or of von Prott, and by judicious restoration. The present writer has to acknowlege a number of errors and omissions in the epigraphical section of the Sparta Museum Catalogue which are set right in this volume.

While it must be of great interest to all students of Greek epigraphy and antiquities, the work will receive a specially warm welcome in this country, in view of the large part taken by the British School at Athens since 1905 in the discovery of new Laconian inscriptions and in securing more exact and trustworthy copies of those already published.

There is a sense in which this volume is final and definitive. Yet inasmuch as the editor has gathered together between its covers most. of the materials necessary for the appreciation and criticism of his labours, it is natural that others should try to check some of his results and, it may be, to carry the work yet a little farther toward perfection. I add notes of a few of the points which have struck me on a first glance through its pages: the fact that the questions dealt with are apparently so trifling must be regarded as my tribute to the success of Professor Kolbe's undertaking.

No. 27. The stone in question is in the Sparta Museum, where it bears the number 446. The text is so mutilated that I did not think it worth while to publish in the Catalogue all I could decipher, but gave only a few words and phrases for purposes of identification. To win as much as he has done is a triumph of von Prott, but unhappily the corrosion of the stone's surface has gone so far that it is impossible to restore a continuous text. 
69, 71. In 69 ll. $30-35$ and in $71 b$ ll. 23-39 we have a list of the

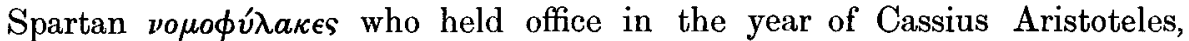
shortly after 150 A.D. The fourth name in each case (69 l. 34, $71 \mathrm{bl}$. 37) is written 月ПEPIK $\wedge \mathrm{H} \Sigma$ upon the stone, and is transcribed by Kolbe, following

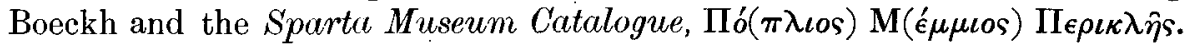
This reading $I$ now regard as untenable. The present case must be treated entirely on its own merits, since this Pericles is not elsewhere mentioned.

In none of the 34 other instances in the present volume in which the collocation П'́m $\lambda \iota \circ$ Mé $\mu \mu \iota$ os occurs do we find this monogram of ПоM used. $\Pi{ }^{\prime} \pi \lambda_{\iota} \circ$ is, it is true, sometimes abbreviated to $\Pi$ (7 times) and far more frequently to $\Pi$ with a small $\circ$ placed inside (15 times) or above it (once, in 197); but Mé $\mu \mu \iota \circ$, though abbreviated eight times to ME, standing separately or in ligature, is never shortened to $M$, and it is extremely unlikely that, even were it so far abbreviated, it would be combined with 0 in a single monogram. ${ }^{1} \quad$ On the other hand, Pomponius is written nine times in full, four times as $\Pi о \mu \pi \dot{\omega}$, once as $\Pi о \mu(546)$, twice as 月 $(37,71 a)$, while Pompeius, which is most frequently written in full, is abbreviated once to $\Pi о \mu \pi \eta^{\prime}$ (557) and seven times to $\Pi o \mu .^{2}$ In four of these last seven cases $\Pi O M$ are written separately, once (170) the $O$ is engraved within the $\Pi$ to which a small $M$ is added by ligature, while twice $(464,11.2,12$ ) we have exactly the monogram of ПоM with which we started.

It seems to me therefore that in 69 and 71 we must read either

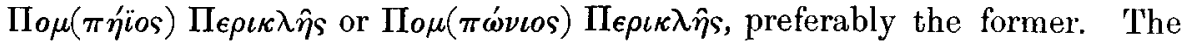
absence of a praenomen need cause us no uneasiness, since the omission is very common and is found on both lists in the case of the following name

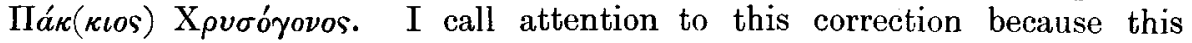
example is frequently adduced to illustrate the lengths to which the Greeks carried their practice of abbreviation (Franz, Elementa, 353).

177. Amongst the cutalogi collegiorum incerti figures a fragment of a list of names, of which the last two are, according to Kolbe's transcription,

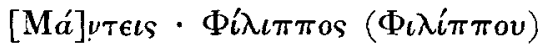

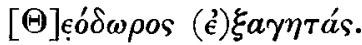

The note is added: ' $\mathfrak{\epsilon} \xi a \gamma \eta \tau$ rás scripsi ratus litteram $E$ a lapicida omissam vel 王 et $\mathrm{E}$ in ligatura $\mathrm{x}$ coniunctas esse.'

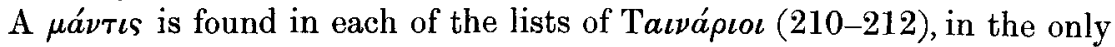
complete list of oi $\sigma \iota \tau \eta \theta$ é $\nu \tau \epsilon s$ (209 1. 13, omitted in the Index) and in that of

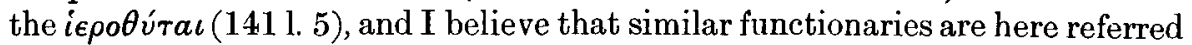
to, though Kolbe has placed them (p. 348 f.) in a different class. Further, I cannot accept é $\xi a \gamma \eta{ }^{a} \mathbf{s}^{\prime}$ : the absence of a patronymic is, though not conclusive,

\footnotetext{
1 M. Aủ $\rho$. is written in monogram on an Attic grave-stone (I.G. iii. 1355), but that belongs to a cunsiderably later date, and the collocation Mareus Aurelius is far commoner than Publius
}

Memmius.

2 I have omitted the monogram of חo $\mu$ in 1483 , for which see my note below. 
against this interpretation, while the only title of this kind known at Sparta-

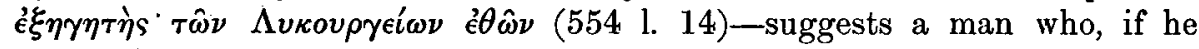
occurred at all in such a list as this, would at least take precedence of his colleague. In 2121.46 a certain $\mathrm{K} \lambda \boldsymbol{\lambda}^{\prime} \omega \nu$ é $\xi$ 'A $\mathrm{y} \dot{\eta} \tau a s$ appears as secretary of

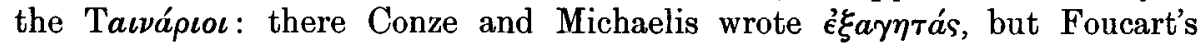
transcription (based on the analogy of numerous examples of a similar use of $\dot{\epsilon} \xi$, $\dot{\epsilon} \kappa$ and $\dot{\epsilon} \gamma$ in 209 and 212) is certainly preferable, and the phrase is to be interpreted 'Cleon freedman of Ageta.' We should, I think, read (') $) \xi$ 'A $\gamma \dot{\eta}$ ' in 177, though the Ageta here referred to can hardly be the same as that of 212 , if the former belongs to the first century after, the latter to the first century before, our era.

$I$ agree with Kolbe in the first part of his statement (p. 70), 'certum

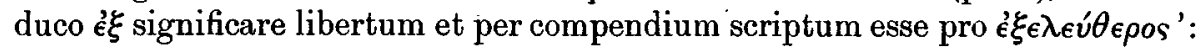
but the second seems to me less likely in view of the fact that 'ُ $\dot{\xi}$ is used

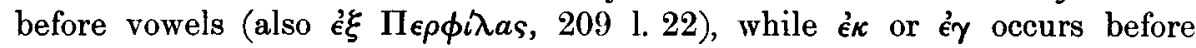
consonants (209 Il. 24, 26, 29). I take it therefore to be the preposition rather than an abbreviation of $\dot{\epsilon} \xi \in \epsilon \epsilon \dot{v} \theta \epsilon \rho o s$.

229. 'Diffido lectioni' is von Wilamowitz's note. But Fraenkel's reading is fully borne out by a copy made by myself when visiting Kalyvia Sochiotika with Professor R. C. Bosanquet in December, 1903, when the inscription was uncovered and thoroughly cleaned. The letters are carefully engraved and are all perfectly clear. A curious fact is that the final $\mathbf{A}$ on the stone is so far from the right hand margin as to make it unlikely that anything followed: if this is so, we have here another example of the use of $\dot{a}$ for $a^{\prime} \nu \epsilon \eta \boldsymbol{\epsilon} \epsilon(-a \nu)$ of which 981 affords an instance.

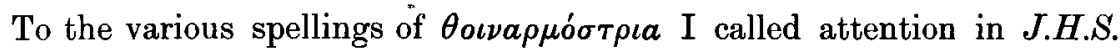
xxv. 50 f., and in J.H.S. xxxii. $100 \mathrm{I}$ gave a list of the occurrences of the word. Owing to changes made in the numeration of I.G. v. i. after the first proofs were in print, No. X should be read 1390 instead of 1388, No. XI. 1447 instead of 1439: No. IX occurs in the present volume among the Addenda as 1511 .

The riddle of the first line I cannot solve, but have a suspicion that in this hyperarchaistic text the mother and father of the dedicatrix may be mentioned, in which case we must read 'O $\beta \rho \rho^{\prime} \mu \omega$ instead of 'O$\beta \rho \iota \mu \omega$. If we accept the latter reading and make it refer to a human being, we are confronted by the difficulty of the singular number in $\sigma \epsilon \iota \nu a \rho \mu \sigma^{\sigma} \tau \rho \eta a$. Or can there be a reference to 'O $\beta \rho \iota \mu \omega$, the by-name of Persephone given us by Lycophron 698 ?

596. In the Addenda (p. 304) Kolbe accepts the reading $\pi a \rho\left(\boldsymbol{a} \delta \boldsymbol{\delta}^{\prime} \boldsymbol{\xi}\right.$ ov) $\dot{a} \rho(\boldsymbol{i} \sigma \tau o v)$, which I suggested in J.H.S. xxxii. 103 on the analogy of what are now I.G. v. i. 305, 554 and $555 b$ : further examples of the same collocation are found in $553,555 a, 628$ and [641].

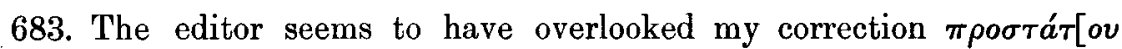

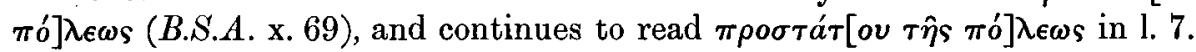


There is, however, no room for the article, and in 547 the same man is

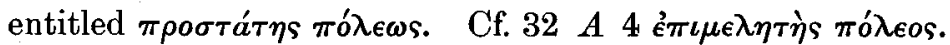

1142. An archaic ex-voto from the village of Marius, written retrograde, has in its first line the dedicator's name

\section{SOTNAMT..}

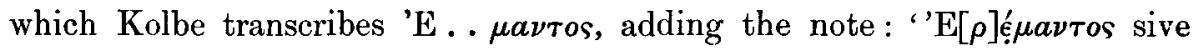

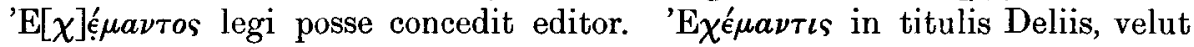
I.G. xi. 199 A 32.' To me a much more probable conjecture seems

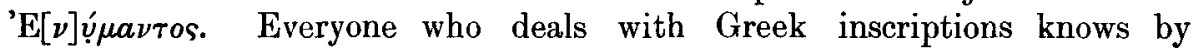
experience how liable $Y$ and $T$ are to be confused, and though the name does not occur elsewhere its existence in Laconia need cause no surprise. For we

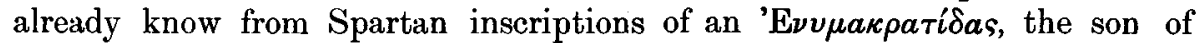

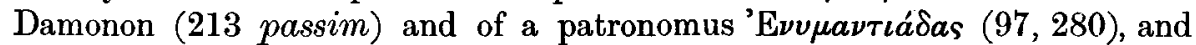

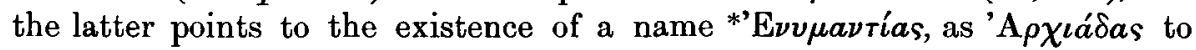

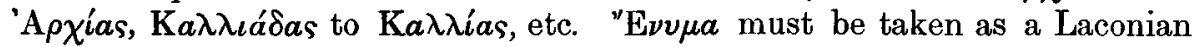
form of ö $\nu \mu_{\mu a}{ }^{3}$ which commonly occurs as ö $\nu v \mu a$ in Dorian dialects, giving

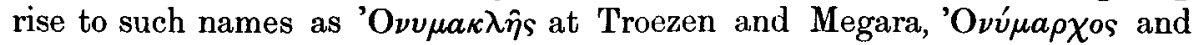

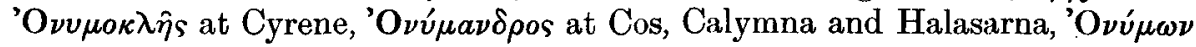
at Corinth and Rhodes, 'O $\nu v \mu \hat{a} s$ at Megara." Bechtel-Fick, Die griech.

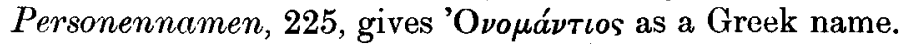

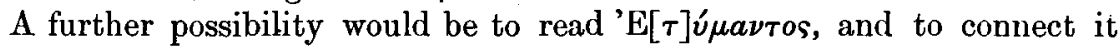

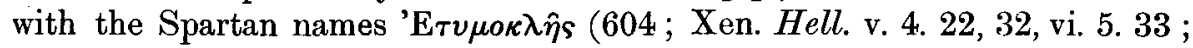

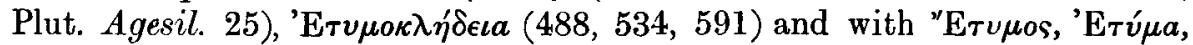
'E $v^{\prime} \mu \omega \nu$,' $\mathrm{E} \tau \nu \mu \omega \dot{\nu} \delta a$ s known from other states. ${ }^{5}$ But this restoration appears to me less probable than the other.

1213. Kolbe rightly interprets the inscription $M$ on a large ball of black marble as equivalent to $\mu(\nu a \hat{\imath}) \eta^{\prime}$. His note is 'sphaera, cuius radius $0,075 \mathrm{~m}$ ponderis habet circa $4600 \mathrm{~g}$ vel, si minam $655 \mathrm{~g}$ habere duxeris, septem minas.' But $\eta$ can hardly bear the value 7 ; it must denote 8 , and the weight of the mina, if the total of the ball is rightly estimated, will be 575 grammes.

1280. If $\mathrm{Z}$ really stands on the stone after the name of Cratesiclea in l. 10, it might be explained, like $\Lambda \mathrm{B}$ in 772 and $K \in$ in 1299 , as giving the age of the deceased, seven years.

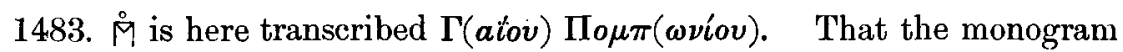
is intended to contain five letters I strongly doubt, still more that it is intended to represent two names. Here too we have to deal, I believe, with a shortened form for $\Pi o \mu(\pi \eta i o v)$ or $\Pi o \mu(\pi \omega \nu i o v)$. See my note on 69 (above).

Marcus N. Tod.

${ }^{3}$ O. Hoffmann, S.G.D.I. iv. 4. 1, p. 694.

4 For references see the Indexes of proper names in S.G.D.I. iv.

${ }^{5}$ Pape-Benseler, Wörterbuch, s.vv. 